\title{
Ultra High-Mass Resolution Paper Spray by Fourier Transform Ion Cyclotron Resonance Mass Spectrometry
}

\author{
Kevin D. Quinn, Charmion I. Cruickshank, and Troy D. Wood \\ Department of Chemistry, State University of New York at Buffalo, Buffalo, NY 14260, USA \\ Correspondence should be addressed to Troy D. Wood, twood@buffalo.edu
}

Received 1 September 2011; Revised 3 February 2012; Accepted 3 February 2012

Academic Editor: Charles L. Wilkins

Copyright ( $) 2012$ Kevin D. Quinn et al. This is an open access article distributed under the Creative Commons Attribution License, which permits unrestricted use, distribution, and reproduction in any medium, provided the original work is properly cited.

\begin{abstract}
Paper Spray Ionization is an atmospheric pressure ionization technique that utilizes an offline electro-osmotic flow to generate ions off a paper medium. This technique can be performed on a Bruker SolariX Fourier transform ion cyclotron resonance mass spectrometer by modifying the existing nanospray source. High-resolution paper spray spectra were obtained for both organic and biological samples to demonstrate the benefit of linking the technique with a high-resolution mass analyzer. Error values in the range 0.23 to $2.14 \mathrm{ppm}$ were obtained for calf lung surfactant extract with broadband mass resolving power $\left(\mathrm{m} / \Delta \mathrm{m}_{50 \%}\right)$ above 60,000 utilizing an external calibration standard.
\end{abstract}

\section{Introduction}

Since the first practical implementation of electrospray ionization (ESI) with mass spectrometry reported by Yamashita and Fenn in 1984, a number of different atmospheric pressure ionization (API) techniques have been developed [3]. Many API techniques require extensive sample preparation as well as costly consumables to obtain mass spectra. One of the most cost effective and widely available media for chemical separation and analysis is paper. It has been shown that an electro-osmotic flow similar to that of static electrospray can be utilized to interface a triangle of wetted paper to a mass spectrometer (MS); this form of analysis is called paper spray (PS) [4-9].

The use of a chromatographic medium such as paper allows for the analysis of complex mixtures since separations will occur as the analyte is being driven along the paper medium [7]. Separating analytes on a paper medium provides the benefits of reduced probability of ion suppression and rapid analysis. The paper medium allows for analysis of complex samples such as biological tissue and dried blood spots which are not suitable for traditional infusion techniques due to their complex matrices $[4,7]$.

One limitation to PS, like many MS techniques that utilize incomplete chromatographic separations is the detector being utilized to perform the analysis. When dealing with complex samples or unknown samples, there is a need for high-quality data in order to determine what is being analyzed. Fourier transform ion cyclotron resonance (FT-ICR) mass spectrometers are powerful tools for analysis of complex mixtures due to their unsurpassed capability to obtain broadband high-resolution mass spectra with high mass accuracy. Utilizing PS with a Fourier transform ion cyclotron resonance (FT-ICR) mass spectrometer as a detector allows for rapid analysis of both unknowns and/or complex mixtures.

In this present work, we show the suitability of a 12 Tesla FT-ICR MS to obtain high-resolution broadband mass spectra utilizing a coffee filter paper spray medium. High-resolution mass spectra were first obtained for polypropylene glycol (PPG) and polyethylene glycol (PEG) standards to test the source. Second, urine and calf lung surfactant extract (CLSE) were analyzed to test the PS source for analysis of complex mixtures not suitable for direct infusion.

\section{Materials, Methods, and Instrumentation}

2.1. Chemicals. All solvents used were HPLC grade obtained from Sigma Aldrich (St. Louis, MO, USA). PPG was obtained in the form of a tuning standard from Applied Biosystems (Bedford, MA, USA). PEG standard was made by dissolving 


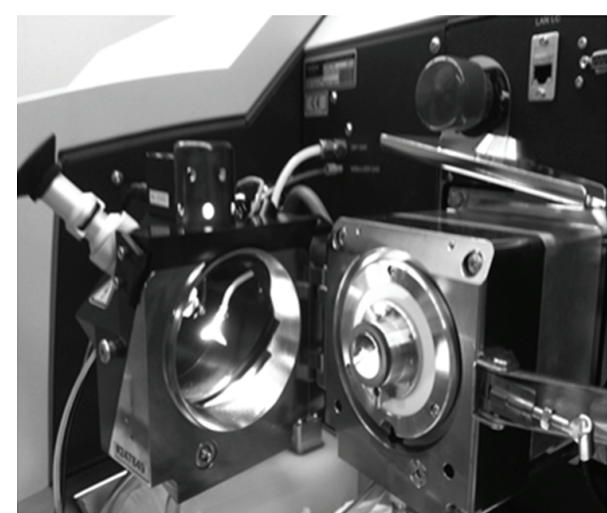

(a)

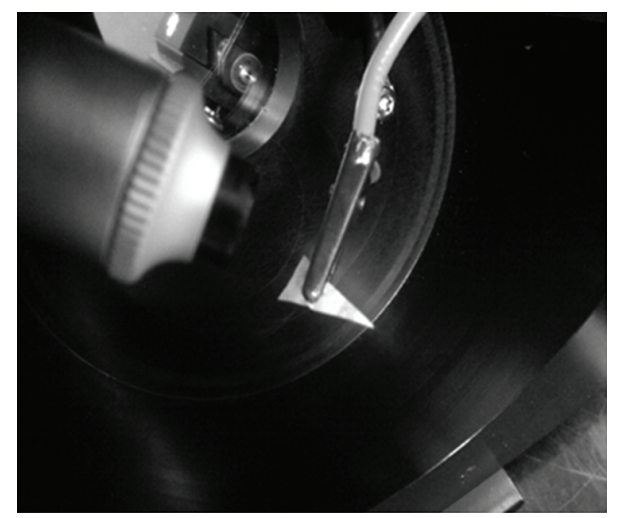

(b)

FIGURE 1: PS source utilizing a modified Bruker nano-ESI source, a copper clip, and cable to ground the paper triangle to the chasse of the instrument.

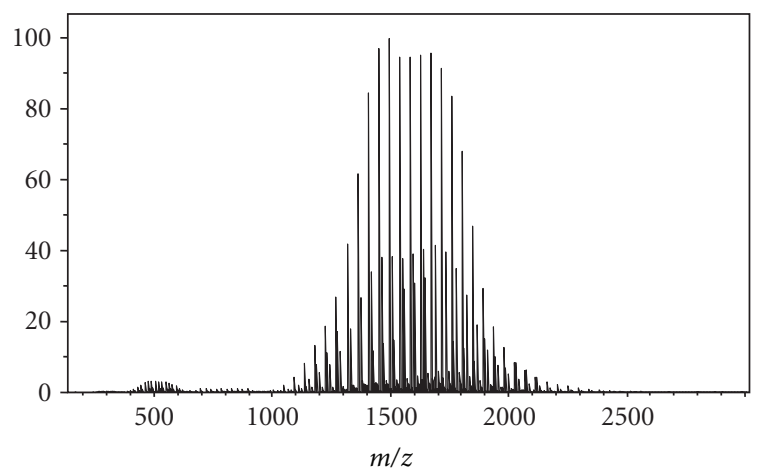

FIGURE 2: Polyethylene glycol paper spray mass spectrum; identification of oligomers as given in the literature [1].

$1 \mathrm{mg}$ of PEG 2000 obtained from Sigma Aldrich (St. Louis, MO, USA) in $1 \mathrm{~mL}$ of HPLC grade water. Coffee filter, Wegmans brand (Rochester, NY, USA), was cut by hand into an isosceles triangle with dimensions of approximately $5 \mathrm{~mm}$ (base) by $10 \mathrm{~mm}$ (height).

2.2. $P P G$ and PEG. Samples for PPG and PEG PS analysis were prepared by wetting the coffee filter triangle with $10 \mu \mathrm{L}$ of the standard solutions. The wet filter paper samples were allowed to dry under ambient conditions before PS analysis was performed. Mass spectra were then obtained by wetting the dried paper triangle with $10 \mu \mathrm{L}$ of $50: 50$ methanol : water and using the method described in Section 2.5.

2.3. CLSE. CLSE was obtained from ONY Inc. (Amherst, NY, USA). Prior to analysis, the sample was stored in chloroform in the refrigerator. Samples for CLSE analysis were produced by wetting a coffee paper triangle with $2 \mu \mathrm{L}$ of CLSE and allowing the sample to dry under ambient conditions before PS analysis was performed. Mass spectra were then obtained by wetting the paper with $10 \mu \mathrm{L}$ of $50: 50$ methanol: water using the instrument method described in Section 2.5.

2.4. Urine. Urine samples were collected from two healthy adult males into sterile polypropylene centrifuge tubes (VWR Scientific) and immediately placed in the freezer. The samples were collected in accordance with the Health Sciences Institutional Review Board at the University at Buffalo (HSIRB no. CHE0050411E). Prior to analysis, the samples were thawed to room temperature and $1 \mathrm{~mL}$ was pipetted into $2 \mathrm{~mL}$ sample vials (Agilent, Santa Clara, CA, USA) for use. Ten $\mu \mathrm{L}$ was injected directly onto a triangular coffee filter and allowed to dry under ambient conditions. Once dry, the filter paper was attached to the mass spectrometer via a copper clip and rewetted using 50:50 methanol: water for PS analysis using the instrument method described in Section 2.5.

2.5. Paper Spray FT-ICR Method. High-resolution spectra were obtained on a $12 \mathrm{~T}$ Bruker SolariX FT-ICR MS (Bruker Daltonics Inc., Billerica, MA, USA) utilizing a modified Bruker nanoelectrospray source. The positive potential was obtained by grounding the paper triangle using a copper clip and applying a negative voltage at the inlet to the mass spectrometer (Figure 1 shows an image of the source). Mass spectra were obtained at various mass to charge ranges with a preFT-ICR-trap hexapole accumulation time of 0.400 seconds and an FT-ICR trap accumulation time of 0.025 seconds. All mass spectra were obtained in the positive mode at a spray voltage of $2 \mathrm{kV}$. Mass resolving power $\left(\mathrm{m} / \triangle \mathrm{m}_{50 \%}\right)$ was defined in accordance with the literature [10].

\section{Results and Discussion}

3.1. Polymer Standards. Polymeric standards were utilized to determine the suitability of PS with high-resolution FTICR MS. In FT-ICR MS the resolution of the mass spectra is relative to $\mathrm{m} / \mathrm{z}$ as well as the number of data points that can be obtained during the detection process. High-resolution spectra require a time domain signal stable for longer than several hundred milliseconds. Polyethylene glycol and polypropylene glycol produce a broad $\mathrm{m} / \mathrm{z}$ range of ions ideal for testing the suitability of PS with high-resolution mass spectrometry. High-resolution mass spectra of PEG and PPG are displayed in Figures 2 and 3, respectively. Identifies of the oligomer ion detected and their associated errors is given in Tables 1 and 2, respectively. 
TABLE 1: PEG standards identified using paper spray mass spectrometry. The PEG mass spectrum was obtained with both an excitation and detection frequency range of $1.5 \mathrm{MHz}$.

\begin{tabular}{|c|c|c|c|c|c|}
\hline PEG & $\begin{array}{c}\text { Experimental } \\
\mathrm{m} / \mathrm{z}\end{array}$ & $\begin{array}{c}\text { Theoretical } \\
m / z\end{array}$ & $\begin{array}{l}\text { Mass measurement } \\
\quad \text { error }(\Delta \mathrm{ppm})\end{array}$ & $\begin{array}{c}\text { Mass resolving } \\
\text { power }\left(\mathrm{M} / \Delta \mathrm{M}_{50 \%}\right)\end{array}$ & {$\left[\mathrm{H}\left(\mathrm{OCH}_{2} \mathrm{CH}_{2}\right)_{n} \mathrm{OH}+\mathrm{Na}\right]^{+}$} \\
\hline & 1009.577639 & 1009.57651 & -0.12 & 46309 & $n=22$ \\
\hline & 1053.60274 & 1053.60273 & 0.01 & 42870 & $n=23$ \\
\hline & 1097.62886 & 1097.62894 & -0.07 & 40306 & $n=24$ \\
\hline & 1141.65527 & 1141.65515 & 0.02 & 38791 & $n=25$ \\
\hline & 1185.68128 & 1185.68137 & -0.08 & 37199 & $n=26$ \\
\hline & 1229.70779 & 1229.70758 & 0.17 & 35953 & $n=27$ \\
\hline & 1273.73391 & 1273.7338 & 0.09 & 34776 & $n=28$ \\
\hline & 1317.76035 & 1317.76001 & 0.26 & 33645 & $n=29$ \\
\hline & 1361.78640 & 1361.78623 & 0.12 & 32579 & $n=30$ \\
\hline & 1405.81232 & 1405.81244 & -0.09 & 31288 & $n=31$ \\
\hline & 1449.83868 & 1449.83866 & 0.01 & 30101 & $n=32$ \\
\hline & 1493.86539 & 1493.86487 & 0.35 & 29219 & $n=33$ \\
\hline & 1537.89172 & 1537.89109 & 0.41 & 28219 & $n=34$ \\
\hline & 1581.91742 & 1581.9173 & 0.08 & 27254 & $n=35$ \\
\hline & 1625.94358 & 1625.94352 & 0.04 & 26391 & $n=36$ \\
\hline & 1669.96968 & 1669.96973 & -0.03 & 25567 & $n=37$ \\
\hline & 1713.99520 & 1713.99595 & -0.44 & 24691 & $n=38$ \\
\hline
\end{tabular}

TABLe 2: PPG standards identified using paper spray mass spectrometry. The PPG mass spectrum was obtained with excitation and detection frequency range of $1.5 \mathrm{MHz}$.

\begin{tabular}{|c|c|c|c|c|c|}
\hline PPG & $\begin{array}{c}\text { Experimental } \\
\mathrm{m} / \mathrm{z}\end{array}$ & $\begin{array}{c}\text { Theoretical } \\
\mathrm{m} / \mathrm{z}\end{array}$ & $\begin{array}{l}\text { Mass measurement } \\
\text { error }(\Delta \mathrm{ppm})\end{array}$ & $\begin{array}{c}\text { Mass resolving } \\
\text { power }\left(\mathrm{M} / \Delta \mathrm{M}_{50 \%}\right)\end{array}$ & {$\left[\mathrm{C}_{3} \mathrm{O}_{2} \mathrm{H}_{7}\left(\mathrm{C}_{3} \mathrm{H}_{6} \mathrm{O}\right)_{n} \mathrm{C}_{6} \mathrm{H}_{13} \mathrm{O}_{2}+\mathrm{Na}\right]^{+}$} \\
\hline & 1666.17197 & 1666.17200 & -0.02 & 22686 & $n=25$ \\
\hline & 1724.21224 & 1724.21386 & -0.94 & 23629 & $n=26$ \\
\hline & 1782.25781 & 1782.25573 & 1.17 & 23817 & $n=27$ \\
\hline & 1840.29829 & 1840.29760 & 0.37 & 23808 & $n=28$ \\
\hline & 1898.34113 & 1898.33946 & 0.88 & 23139 & $n=29$ \\
\hline & 1956.37992 & 1956.38133 & -0.72 & 22968 & $n=30$ \\
\hline & 2014.41937 & 2014.42319 & -1.90 & 22638 & $n=31$ \\
\hline & 2072.46849 & 2072.46505 & 1.66 & 21991 & $n=32$ \\
\hline & 2130.50088 & 2130.50692 & -2.84 & 21503 & $n=33$ \\
\hline & 2188.55370 & 2188.54878 & 2.25 & 20679 & $n=34$ \\
\hline & 2246.59219 & 2246.59065 & 0.69 & 19685 & $n=35$ \\
\hline & 2304.63182 & 2304.63254 & -0.31 & 17868 & $n=36$ \\
\hline & 2362.67370 & 2362.67438 & -0.29 & 16365 & $n=37$ \\
\hline
\end{tabular}

Signal-to-noise obtained for PEG and PPG after tuning spectra was in excess of $100 / 1$ with absolute intensities that varied shot-to-shot by less than $20 \%$. This allowed ample time for adjustment of the filter paper towards the inlet of the mass spectrometer so as to optimize instrument setup and analysis. Utilizing polymers of known $M_{n}$ values (provided by the manufacturers; polydispersity not given) such as PEG 2000 and PPG 2000 provides a detection window several hundred $\mathrm{m} / \mathrm{z}$ wide for broad mass accuracy calibrations for FT-ICR MS.
3.2. Calf Lung Surfactant Extract. Calf lung surfactant extract (CLSE), which is commercially available in drug form as Infasurf, is used to treat respiratory distress syndrome [11]. CLSE is obtained by doing a total lipid extraction on the lavage fluid from a slaughtered calf lung [11, 12]. Phosphatidylcholine (PC) makes 79\% of the molar distribution of lipids and consists of a choline head group attached to the phospholipid with varying degrees of unsaturation in the fatty acid chains [2]. Based on the optimized setup determined from previously analyzing the standards, CLSE was then 
TABLE 3: CLSE compounds identified using paper spray mass spectrometry. The phospholipids detected are denoted using the lipid numbers nomenclature to indicate degrees of unsaturation, and PC refers to phosphatidylcholine. The CLSE mass spectrum was obtained with excitation and detection frequency range of $1.5 \mathrm{MHz}$.

\begin{tabular}{|c|c|c|c|c|}
\hline $\begin{array}{l}\text { Experimental } \\
m / z\end{array}$ & $\begin{array}{l}\text { Theoretical } \\
\mathrm{m} / \mathrm{z}\end{array}$ & $\begin{array}{l}\text { Mass measurement } \\
\text { error }(\Delta \mathrm{ppm})\end{array}$ & $\begin{array}{c}\text { Mass resolving } \\
\text { power }\left(\mathrm{M} / \Delta \mathrm{M}_{50 \%}\right)\end{array}$ & Compound \\
\hline 728.52151 & 728.52008 & 1.96 & 61637 & $16: 0 / 14: 0 \mathrm{PC}[\mathrm{M}+\mathrm{Na}]^{+}$ \\
\hline 732.55505 & 732.55378 & 1.73 & 60967 & $\begin{array}{l}16 / 16 \mathrm{PC}[\mathrm{M}+\mathrm{H}]^{+} 1 \text { degree } \\
\text { of unsaturation }\end{array}$ \\
\hline 734.57100 & 734.56943 & 2.14 & 62820 & $16: 0 / 16: 0 \mathrm{PC}[\mathrm{M}+\mathrm{H}]^{+}$ \\
\hline 754.53660 & 754.53572 & 1.17 & 57074 & $\begin{array}{c}16 / 16 \mathrm{PC}[\mathrm{M}+\mathrm{Na}]^{+} 1 \\
\text { degree of unsaturation }\end{array}$ \\
\hline 756.55257 & 756.55137 & 1.59 & 57597 & $16: 0 / 16: 0 \mathrm{PC}[\mathrm{M}+\mathrm{Na}]^{+}$ \\
\hline 760.58591 & 760.58508 & 1.09 & 55950 & $\begin{array}{c}16 / 18 \mathrm{PC}[\mathrm{M}+\mathrm{H}]^{+} 1 \text { degree } \\
\text { of unsaturation }\end{array}$ \\
\hline 782.56728 & 782.56702 & 0.33 & 52802 & $\begin{array}{c}16 / 18 \mathrm{PC}[\mathrm{M}+\mathrm{Na}]^{+} 1 \\
\text { degree of unsaturation }\end{array}$ \\
\hline 798.54114 & 798.54096 & 0.23 & 48188 & $\begin{array}{c}16 / 18 \mathrm{PC}[\mathrm{M}+\mathrm{K}]^{+} 1 \text { degree } \\
\text { of unsaturation }\end{array}$ \\
\hline 808.58322 & 808.58267 & 0.68 & 48764 & $\begin{array}{c}18 / 18 \mathrm{PC}[\mathrm{M}+\mathrm{Na}]^{+} 2 \\
\text { degrees of unsaturation }\end{array}$ \\
\hline
\end{tabular}

TABLE 4: Compounds identified using paper spray mass spectrometry on urine sample from 27 -year-old volunteer. The urine mass spectrum was obtained with both an excitation and detection frequency range of $1.5 \mathrm{MHz}$.

\begin{tabular}{|c|c|c|c|c|c|}
\hline Compound & Species & Formula & $\begin{array}{c}\text { Experimental } \\
\mathrm{m} / \mathrm{z}\end{array}$ & Theoretical $\mathrm{m} / \mathrm{z}$ & $\begin{array}{l}\text { Mass measurement } \\
\quad \text { error }(\Delta \mathrm{ppm})\end{array}$ \\
\hline $\begin{array}{l}\text { 3-Hexaprenyl-4,5- } \\
\text { Dihydroxybenzoic } \\
\text { acid }\end{array}$ & {$[\mathrm{M}+\mathrm{Na}]$} & $\mathrm{C}_{37} \mathrm{H}_{54} \mathrm{O}_{4} \mathrm{Na}$ & 585.39288 & 585.39143 & 2.5 \\
\hline $\begin{array}{l}\text { 3'-hydroxy-e,e-caroten- } \\
\text { 3-one }\end{array}$ & {$\left[\mathrm{M}+\mathrm{CH}_{3} \mathrm{OH}+\mathrm{H}\right]$} & $\mathrm{C}_{41} \mathrm{H}_{59} \mathrm{O}_{3}$ & 599.44790 & 599.44587 & 3.4 \\
\hline $\begin{array}{l}\text { Vitamin D2 } \\
\text { 3-glucuronide }\end{array}$ & {$\left[\mathrm{M}+\mathrm{CH}_{3} \mathrm{OH}+\mathrm{H}\right]$} & $\mathrm{C}_{35} \mathrm{H}_{57} \mathrm{O}_{8}$ & 605.40328 & 605.40480 & 2.5 \\
\hline Coenzyme Q10 & {$[\mathrm{M}+\mathrm{K}]$} & $\mathrm{C}_{59} \mathrm{H}_{90} \mathrm{O}_{4} \mathrm{~K}$ & 901.64549 & 901.64707 & 1.8 \\
\hline
\end{tabular}

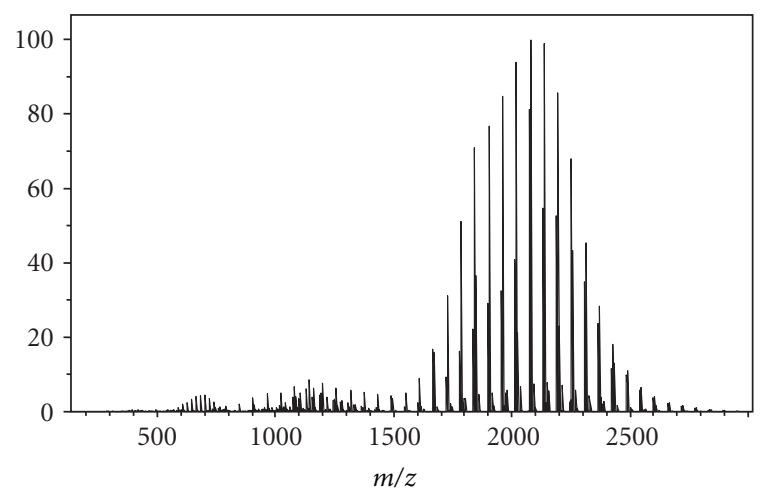

Figure 3: Polypropylene glycol paper spray mass spectrum; identifications of oligomers as given in the literature [2].

analyzed. PS mass spectra of CLSE are given in Figures 4 and 5 , and the identities with associated error provided in Table 3.

3.3. Urine. Due to the complex nature of urine, many small molecules and metabolites were detected at varying intensities using PS with FT-ICR. PS mass spectra, showing

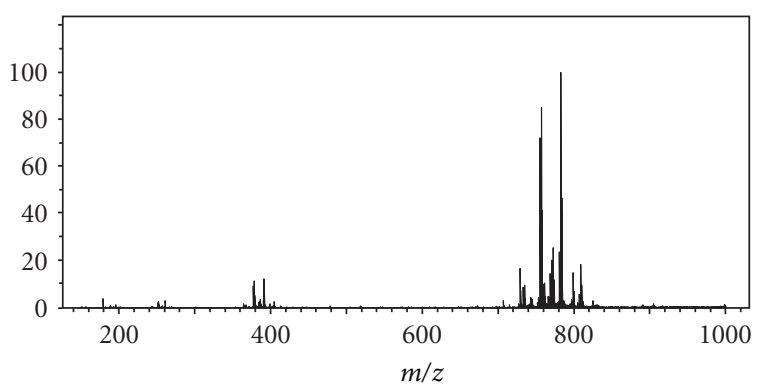

FIGURE 4: Broadband PS mass spectrum of $2 \mu \mathrm{L}$ CLSE, the spectrum was obtained by signal averaging 48 scans (arbitrary).

numerous lipids and other metabolites obtained from the analyzed urine specimens of two healthy adult male subjects, are shown in Figure 6; an inset of one of these PS mass spectra is shown in Figure 7 while the other is shown in Figure 8. A few of the metabolites identified in the 27-year-old volunteer using the exact mass capability of FT-ICR are provided in Table 4. Metabolites identified in the 44-year-old volunteer using the exact mass capability of FT-ICR are 
TABLE 5: Compounds identified using paper spray mass spectrometry on urine sample from 44 -year-old volunteer. The urine mass spectrum was obtained with excitation and detection frequency range of $1.5 \mathrm{MHz}$.

\begin{tabular}{|c|c|c|c|c|c|}
\hline Compound & Species & Formula & Experimental $\mathrm{m} / \mathrm{z}$ & Theoretical $\mathrm{m} / \mathrm{z}$ & $\begin{array}{l}\text { Mass measurement } \\
\text { error }(\Delta \mathrm{ppm})\end{array}$ \\
\hline Vitamin $\mathrm{K} 1$ & {$[\mathrm{M}+\mathrm{K}]$} & $\mathrm{C}_{31} \mathrm{H}_{46} \mathrm{O}_{2} \mathrm{~K}$ & 489.31176 & 489.31294 & 2.4 \\
\hline $\begin{array}{l}\text { 16-alpha, } 17 \text {-beta-estriol } \\
\text { 17-beta-D-glucuronide }\end{array}$ & {$\left[\mathrm{M}+\mathrm{CH}_{3} \mathrm{OH}+\mathrm{H}\right]$} & $\mathrm{C}_{25} \mathrm{H}_{37} \mathrm{O}_{10}$ & 497.23617 & 497.23812 & 3.9 \\
\hline $\begin{array}{l}\text { Tetrahydroaldosterone-3- } \\
\text { glucuronide }\end{array}$ & {$[\mathrm{M}+\mathrm{H}]$} & $\mathrm{C}_{27} \mathrm{H}_{41} \mathrm{O}_{11}$ & 541.26279 & 541.26434 & 2.9 \\
\hline $\begin{array}{l}\text { 25-Hydroxyvitamin } \\
\text { D2-25-glucuronide }\end{array}$ & {$\left[\mathrm{M}+\mathrm{CH}_{3} \mathrm{OH}+\mathrm{H}\right]$} & $\mathrm{C}_{35} \mathrm{H}_{57} \mathrm{O}_{9}$ & 621.39946 & 621.39971 & 0.4 \\
\hline
\end{tabular}

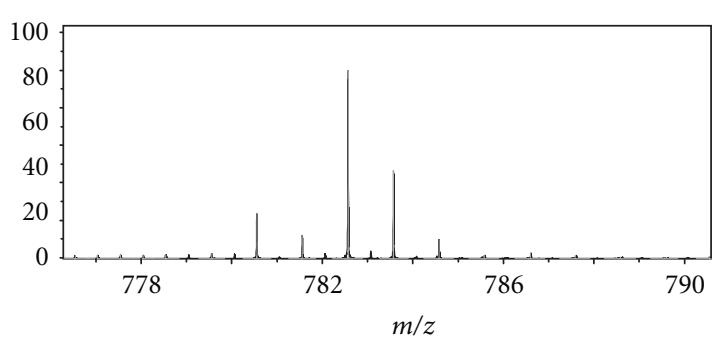

FIGURE 5: Inset of broadband PS mass spectrum of CLSE over $\mathrm{m} / \mathrm{z}$ 776-791.

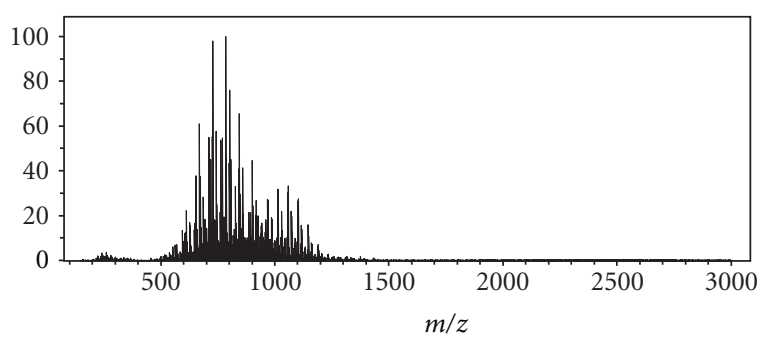

(a)

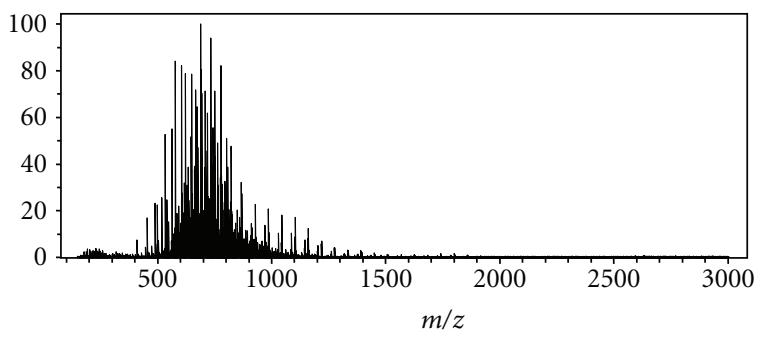

(b)

FIGURE 6: PS mass spectra of urine specimens from two healthy male individuals: 27 year-old (a) and 44 year-old (b).

given in Table 5. Of note, the 44-year-old volunteer, who was taking prescribed vitamin D supplements, showed indications of the vitamin D metabolite 25-Hydroxyvitamin D225-glucuronide in the urine. Interestingly, both adult male subjects had indications of one or more glucuronides in urine. This may signal a particularly strong propensity for glucuronides to ionize via the PS ionization mechanism; this capability of PS should be further explored.

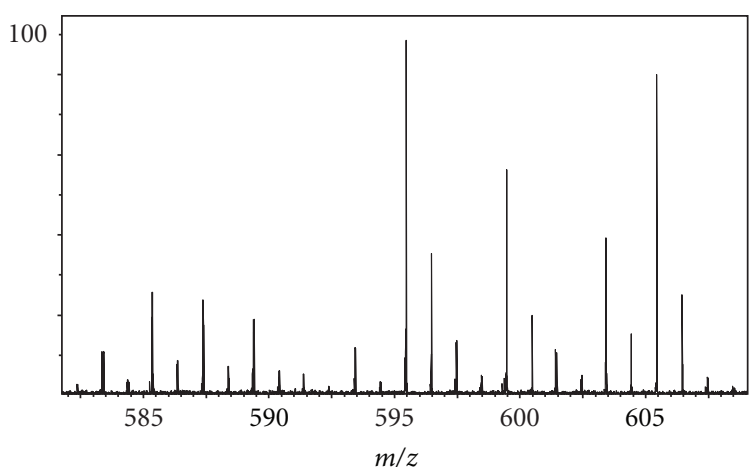

FIGURE 7: Inset of PS mass spectrum for urine specimen from 27year-old volunteer over $m / z$ 582-608.

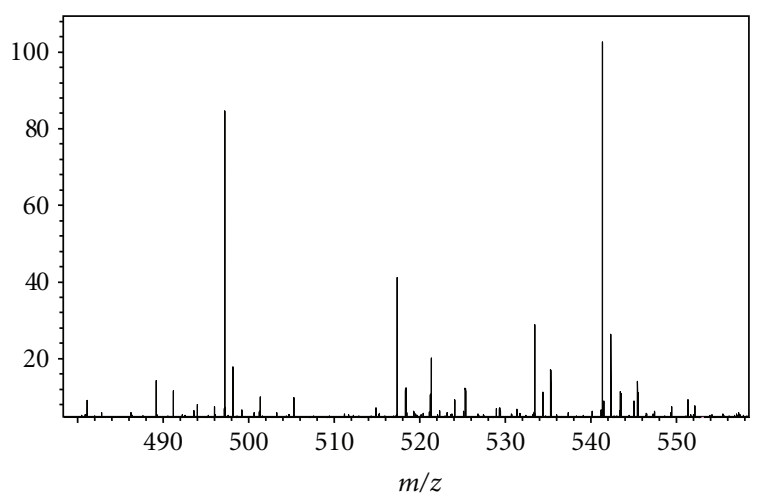

FIGURE 8: Inset of PS mass spectrum for urine specimen from 44 -year-old volunteer being treated with prescription vitamin $\mathrm{D}$ supplement over $m / z$ 480-560.

\section{Conclusions}

We developed a PS source for Bruker FT-ICR instrumentation that can be utilized for a broad range of chemical species. The PS source was tested on a range of samples and determined the source was suitable for both polymer and biological samples. The PS source provided an API medium for the analysis of complex mixtures while mitigating the possibility of cross contamination due to the disposable nature of coffee filter paper. 


\section{Nomenclature}

ESI: Electrospray ionization

API: Atmospheric pressure ionization

MS: $\quad$ Mass spectrometer

PS: $\quad$ Paper spray

FT-ICR: Fourier transform ion cyclotron resonance

PPG: $\quad$ Polypropylene glycol

PEG: Polyethylene glycol

CLSE: Calf lung surfactant extract

PC: Phosphatidylcholine

HSIRB: Health Sciences Institutional Review Board.

\section{Acknowledgments}

Donation of the CLSE sample from ONY, Inc. and funding from the National Institutes of Health for the 12-tesla FT-ICR (S10RR029517 to T.D.W.) is gratefully acknowledged. This paper is dedicated in remembrance of Dr. Bruce A. Holm.

\section{References}

[1] G. Montaudo, M. S. Montaudo, C. Puglisi, and F. Samperi, "Characterization of polymers by matrix-assisted laser desorption ionization-time of flight mass spectrometry. End group determination and molecular weight estimates in poly(ethylene glycols)," Macromolecules, vol. 28, no. 13, pp. 4562-4569, 1995.

[2] A. T. Jackson, S. E. Slade, K. Thalassinos, and J. H. Scrivens, "End-group characterisation of poly(propylene glycol)s by means of electrospray ionisation-tandem mass spectrometry (ESI-MS/MS)," Analytical and Bioanalytical Chemistry, vol. 392, no. 4, pp. 643-650, 2008.

[3] M. Yamashita and J. B. Fenn, "Electrospray ion source. Another variation on the free-jet theme," Journal of Physical Chemistry, vol. 88, no. 20, pp. 4451-4459, 1984.

[4] H. Wang, N. E. Manicke, Q. Yang et al., "Direct analysis of biological tissue by paper spray mass spectrometry," Analytical Chemistry, vol. 83, no. 4, pp. 1197-1201, 2011.

[5] L. Anyin, H. Wang, Z. Ouyang, and R. G. Cooks, "Paper spray ionization of polar analytes using non-polar solvents," Chemical Communications, vol. 47, no. 10, pp. 2811-2813, 2011.

[6] J. Liu, H. Wang, N. E. Manicke, J. M. Lin, R. G. Cooks, and Z. Ouyang, "Development, characterization, and application of paper spray ionization," Analytical Chemistry, vol. 82, no. 6, pp. 2463-2471, 2010.

[7] H. Wang, J. Liu, R. Graham Cooks, and Z. Ouyang, "Paper spray for direct analysis of complex mixtures using mass spectrometry," Angewandte Chemie, vol. 49, no. 5, pp. 877-880, 2010.

[8] R. G. Cooks, N. E. Manicke, A. L. Dill et al., "New ionization methods and miniature mass spectrometers for biomedicine: DESI imaging for cancer diagnostics and paper spray ionization for therapeutic drug monitoring," Faraday Discussions, vol. 149, pp. 247-267, 2011.

[9] R. Haddad, H. M. S. Milagre, R. R. Catharino, and M. N. Eberlin, "Easy ambient sonic-spray ionization mass spectrometry combined with thin-layer chromatography," Analytical Chemistry, vol. 80, no. 8, pp. 2744-2750, 2008.

[10] A. G. Marshall, C. L. Hendrickson, and G. S. Jackson, "Fourier transform ion cyclotron resonance mass spectrometry: a primer," Mass Spectrometry Reviews, vol. 17, no. 1, pp. 1-35, 1998.

[11] R. H. Notter, E. A. Egan, and M. S. Kwong, "Lung surfactant replacement in premature lambs with extracted lipids from bovine lung lavage: effects of dose, dispersion technique, and gestational age," Pediatric Research, vol. 19, no. 6, pp. 569-577, 1985.

[12] E. G. Blugh and W. J. Dyer, "A rapid method of total lipid extraction and purification," Canadian Journal of Biochemistry and Physiology, vol. 37, no. 8, pp. 911-917, 1959. 


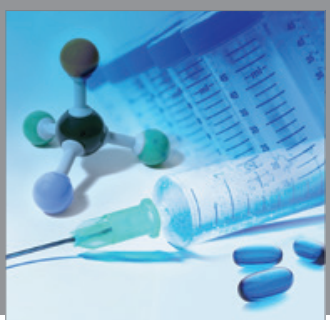

International Journal of

Medicinal Chemistry

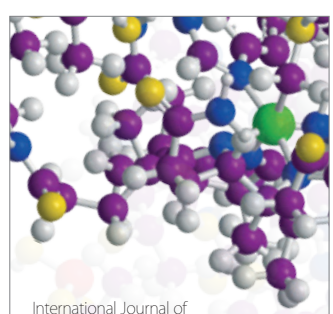

Carbohydrate Chemistry

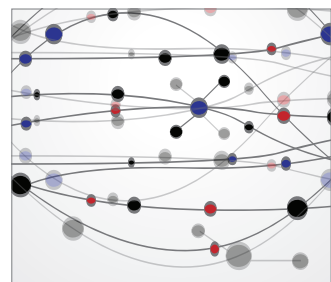

The Scientific World Journal
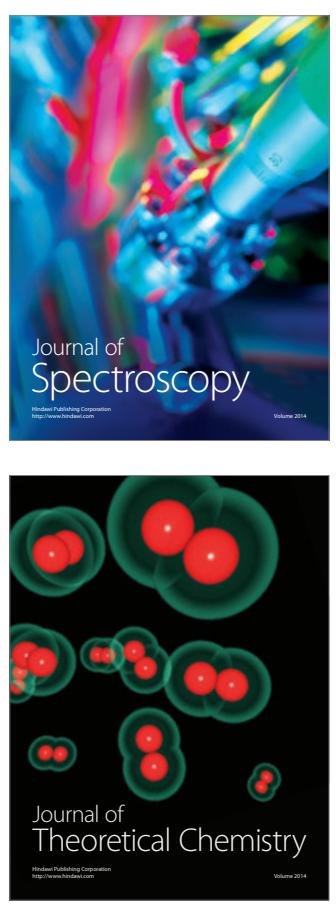
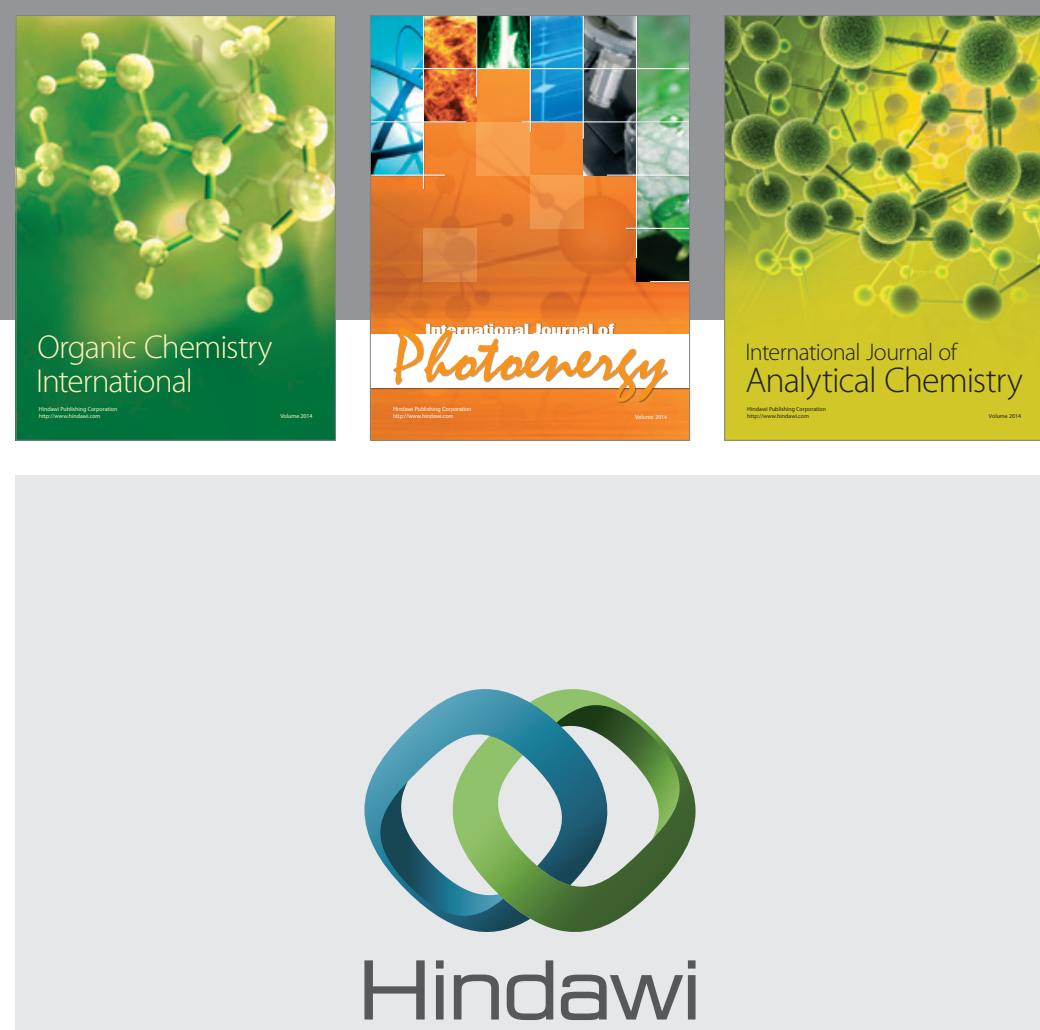

Submit your manuscripts at

http://www.hindawi.com
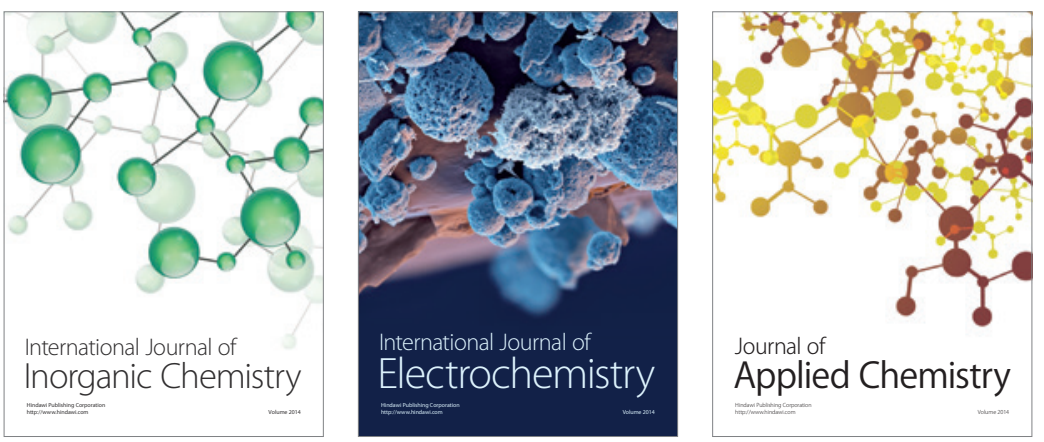

Journal of

Applied Chemistry
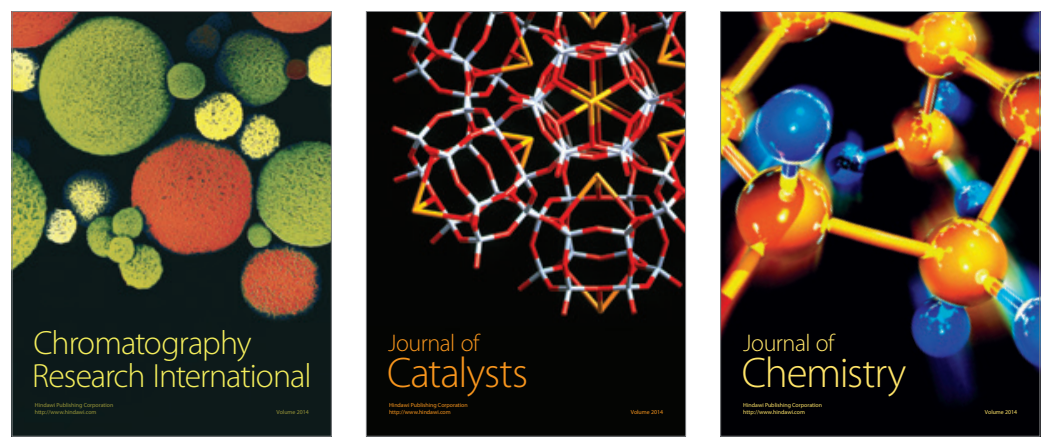
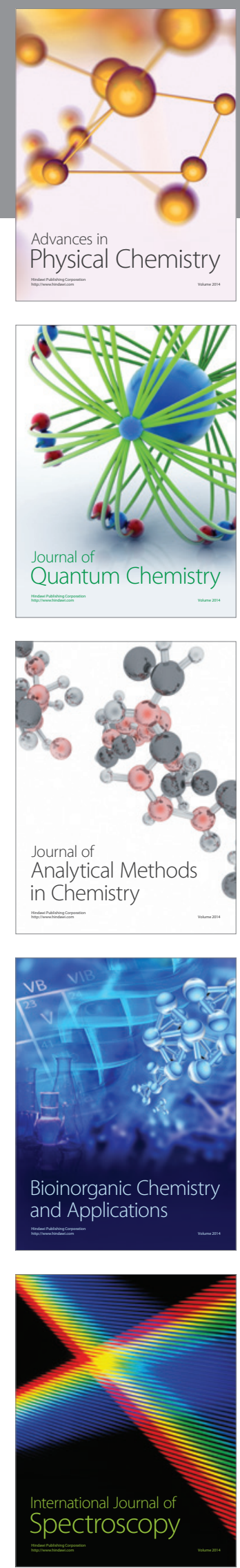